Article

\title{
Utilizing Webs to Share Ancestral and Intergenerational Teachings: The Process of Co-Building an Online Digital Repository in Partnership with Indigenous Communities
}

\author{
Derek Jennings ${ }^{1, *}$, Michelle Johnson-Jennings ${ }^{1,2,3}$ and Meg Little ${ }^{4}$ (D) \\ 1 Community Health and Epidemiology, University of Saskatchewan, Saskatoon, SK S7N 5A2, Canada; \\ mjohnsonjennings@usask.ca \\ 2 School of Social Work, University of Washington, Seattle, WA 98195, USA \\ 3 Indigenous Community Health (RICH) Center, University of Colorado, Boulder, CO 80309, USA \\ 4 Department of Pharmacy Practice and Pharmaceutical Sciences, University of Minnesota, Minneapolis, \\ MN 55455, USA; littlem@d.umn.edu \\ * Correspondence: drj@usask.ca; Tel.: +1-306-966-5655
}

Received: 5 May 2020; Accepted: 15 June 2020; Published: 1 July 2020

check for updates

\begin{abstract}
Indigenous knowledge and wisdom continue to guide food and land practices, which may be key to lowering high rates of diabetes and obesity among Indigenous communities. The purpose of this paper is to describe how Indigenous, ancestral, and wise practices around food and land can best be reclaimed, revitalized, and reinvented through the use of an online digital platform. Key informant interviews and focus groups were conducted in order to identify digital data needs for food and land practices. Participants included Indigenous key informants, ranging from elders to farmers. Key questions included: (1) How could an online platform be deemed suitable for Indigenous communities to catalogue food wisdom? (2) What types of information would be useful to classify? (3) What other related needs exist? Researchers analyzed field notes, identified themes, and used a consensual qualitative research approach. Three themes were found, including a need for the appropriate use of Indigenous knowledges and sharing such online, a need for community control of Indigenous knowledges, and a need and desire to share wise practices with others online. An online Food Wisdom Repository that contributes to the health and wellbeing of Indigenous peoples through cultural continuity appears appropriate if it follows the outlined needs.
\end{abstract}

Keywords: indigenous health; world wide web; wise practices; digital repository; ancestral teachings

\section{Introduction}

They're going to tell you a lot everyday .... You're going to like knowing everybody around you, area, the people, you know, telling you something every day. (Referenced flying objects in the skies.) It's going to be just like that. You're going to know everything, what's going on in the world ... . Even, we going to have a spider web all over the country. Spider web's going to cover us-Prophecy by Choctaw hopaii/prophet in the early 1900s. (referenced in Mould 2003, p. 55)

Historically, Choctaw hopaii were storytellers of wisdom that crossed generations and time. While the above Indigenous Choctaw prophecy arose nearly a century ago, the second author, a Choctaw tribal member, interpreted it as predicting the importance of being connected and delivering information through the World Wide Web, herein referred to as the Web. While the hopaii's role in the 
community was diminished through colonization, their lasting impact and prophecies continue to guide successive generations into the digital age and can help us realize technology's full potential. For instance, the Web currently hosts Indigenous ancestral knowledge transmission and facilitates social connections around the world, among many Indigenous persons. Yet, critical questions arise regarding how to implement the teachings of previous generations within contemporary times. The purpose of this paper is to describe Indigenous communities' needs regarding how best to reclaim and revitalize food and land practices through the use of an online digital platform. The term "wise" is used instead of "best" practices to indicate centering Indigenous worldviews. Wise practices further refer to the use of Indigenous Knowledges (IKs) that inform locally appropriate actions, tools, principles, or decisions and contribute to the development of sustainable health practices (Johnson-Jennings et al. 2019). Use of wise practices also counters the assumption that what is best for one group is generalizable to all others, as is implied by the reference to best practices (Wesley-Esquimaux and Calliou 2010; Thoms 2007).

\subsection{Cultural Continuity: Transmission through Online Platforms}

Online platforms may support continuity of cultural food and land practices if Indigenous people are in control of its implementation. Across centuries, Indigenous cultures have been at the forefront of gathering new technology and reinventing its utility. For instance, Indigenous nations are widely known to have quickly obtained glass beads and then integrated them into creating Indigenous regalia and other traditional works, substituting difficult-to-obtain shells, pearls, stones, copper, dyed porcupine quills, and the like. The glass bead technology increased the efficiency of transmitting cultural symbols and designs through established patterns and codes, thereby also increasing transmission of ancestral knowledges. In this manner, Indigenous communities exercised sovereignty and self-determination in using novel technology. Today, online and social media platforms have been used to effectively disseminate cultural information and create online communities among Indigenous peoples in efficient and self-determined manners. For example, in 2007, the Center for Digital Scholarship and Curation at Washington State University developed the Mukurtu Wumpurrarni-kari Archive (Center for Digital Scholarship and Curation at Washington State University 2019). This platform serves as a community-driven, open source content management system that meets the "needs of diverse communities who want to manage and share their digital cultural heritage" on their own terms. Idle No More is another recent digital social movement that illustrates the power of connecting with those around the world for social justice and change (Tupper 2014). In both examples, digital online platforms remain important for not only connecting with others, but also for maintaining cultural practices, which can further cultural continuity (see Champagne 2007). Research indicates that if cultural continuity is increased, so do health outcomes (Chandler and Lalonde 1998; Oster et al. 2014). Therefore, Indigenous communities may support cultural continuity, and thereby improve their health outcomes, through the use of culturally situated digital tools.

\subsection{The New Smoke Signals: Digital Technology as a Potential Form of Disseminating Indigenous Knowledge}

Several Indigenous cartoons or memes depict social media and technology as the new smoke signals, i.e., the ability to communicate with other Indigenous groups across great distances. Digital platforms have been seen to share Indigenous knowledge (IK) appropriately and to efficiently transmit this information to many at once (Hunter 2005). In fact, digital repositories can hold cultural artifacts and disseminate cultural beliefs, teachings, and practices in a culturally appropriate manner (Hennessy et al. 2013). This is especially important for Indigenous communities who have been historically fragmented, or isolated, through colonization and lack access to elders, knowledge keepers, and/or other readily available access to this information. Furthermore, digital platforms can unite Indigenous persons efficiently over commonly held interests. In essence, an online social network may be just as powerful as in-person networks, and perhaps more efficient. Given that Indigenous people are often marginalized in the media, digital platforms can inform cross-national Indigenous communities about pressing issues and call for immediate global responses. Such quick responses were seen with 
the aforementioned Idle No More movement. The Web rapidly connected Indigenous communities around the world in order to form online communities, share information, and organize protests for social change. One element of this Web-based communication resulted in organized "flash mobs", which rapidly occurred in unison in various public venues across the world (Tupper 2014).

Digital platforms can further increase cultural continuity, or furthering of cultural practices, and encourage revitalization around food practices. Unfortunately, colonization has systematically dismantled many Indigenous families, community kinship networks, and land connections that provided emotional, spiritual, and physical support and guided cultural transmission of traditional ways (Saslis-Lagoudakis et al. 2014). Yet, IKs have survived in the pockets of communities and families across the world in various forms. Though IKs continue to be transmitted, sometimes remaining IK was protected and not shared with the younger generations for fear that they too would be oppressed if they maintained these practices. Others, perhaps, did not share IKs with the younger generations out of fear of cultural appropriation and/or misuse of IKs by outsiders (Johnson-Jennings et al. forthcoming). As a result, IKs sometimes became so heavily guarded that communities could not actively evolve or transform their cultural knowledges to fit modern-day life. Furthermore, IKs are often land-based and, by default, may consequently not be shared outside of the local geographic area. Given the removal of many Indigenous persons from their tribal homelands and related original IK, they may now share more IKs in common with the communities on whose homelands they currently reside. As a result, ancestral cultural information has become fragmented and sometimes inaccessible (Nelson 2008), leaving some Indigenous groups wanting to reconnect with the IK of their tribes via digital methods (Saslis-Lagoudakis et al. 2014).

Online digital platforms that are controlled by Indigenous communities can ensure dissemination of cultural knowledges in appropriate ways. They can further provide an opportunity to revitalize and reclaim IKs regarding land, medicines, and foods, as more communities may provide ongoing feedback to build and validate the data. For example, knowledge of Indigenous herbal medicines and their evolution is related to an Indigenous group's environment or place, which includes how climate change has impacted these medicines (Lynn 2013). This invaluable information could be shared, for example, with Indigenous persons who live in a region differing from their tribal homelands through an online IK repository. The individuals could also learn about the medicines that grow locally and how they relate to the medicines belonging to their tribal homelands. Elders could augment this information with stories or experiences, as appropriate, for others to learn. Though digital platforms will not replace the physical connections to the land or to elders' teachings, there exists potential to provide the resources and initial direction to guide knowledge creation, sharing, and reclamation.

\subsection{Re-Storying through Digital Spaces}

Digital spaces can serve as excellent storytelling platforms, which may be particularly important for Indigenous communities. Especially given that Indigenous communities have moved from solely surviving colonial genocide and ethnocide to a place of Indigenous persons promoting health and wellbeing on their own terms (Walters et al. 2018). Furthermore IKs center on relationality to past, present, and future ancestors and the environment (Moreton-Robinson et al. 2017) and have been transmitted through storytelling for centuries, especially in regards to original instructions (OI), which refer to ancestral protocols that focus on relationships to others and the environment (Nelson 2008). Today, Indigenous scholars and communities are seeking innovative means to support relational approaches for wellbeing in today's world (Martin and Mirraboopa 2003). Thus, the Web can serve as one innovative method to present Indigenous stories in a culturally relevant and relational manner while creating present-day and future solutions. For example, several Indigenous grassroots methods exist for sharing Indigenous knowledge systems in order to support thrivance, "or moving towards supporting existing health and wellbeing as guided by OI and the community" (p. S57 Walters et al. 2018). To do so, Indigenous persons must control the comprehensive management of such stories or data to ensure accuracy, validity, reliability, and fidelity. 
Indigenous stories are embedded with IKs and cultural protocols. Place-based teachings, relational worldviews, and ways of being, knowing, and communicating in the world are embedded in IKs and Indigenous stories. OIs are learned and interpreted by the subsequent generations through formal and informal teaching processes, often through stories (Nelson 2008). In doing so, Indigenous ancestors and communities have been given practices and protocols for how to live and interact in the world (Nelson 2008). Thus, attempts at health interventions that ignore this relationship may not be as effective as those incorporating OIs and related IKs. As the Choctaw hopaii suggested, the Web can bring together Indigenous peoples across the world, while also holding promise for cultural perpetuity. In particular, health interventions that include narrative transformation can serve to decolonize internalized and embodied narratives of victimization into narratives of hope and wellbeing (Walters et al. 2018). This has been done by Indigenous communities for centuries through stories, art, song, ceremonies, and dance. Because Indigenous community members maintain, or have access to, internet connections and obtain information online as their preferred/primary source of health information (Donelle and Hoffman-Goetz 2008), an online platform may be an appropriate place for stories and building relationships across the web. More specifically, digital spaces can be indigenized, or centered within IKs and OIs, in order to promote narratives of hope and healing instead of narratives of disparities and trauma, which are often highlighted in the research. Thus, this study sought to identify community needs regarding a digital online platform and how best to develop a culturally appropriate repository, which would allow the communities to reclaim, revitalize, and reinvent food and land practices on their own terms.

\section{Methods}

After a year of development, the authors began an initial online framework for a community-engaged Indigenous Food Wisdom Repository (Repository) in February 2016. Dr. Johnson-Jennings (Choctaw) is the Primary Investigator (PI), Dr. Jennings (Sac and Fox and Quapaw) is the Co-Principal Investigator (CoPI), and Dr. Little (ally) is the Co-investigator (Co-I). The positionalities of the researchers include Dr. Jennings being an Indigenous health educator and professor from the Anishinaabe Sac and Fox tribe as well as the Quapaw Dhegihan Sioux tribe. Dr. Johnson-Jennings is a Choctaw Nation Indigenous clinical health psychologist, professor, and research center director. Both Dr. Jennings and Johnson-Jennings have decades of experience engaging with Indigenous communities, organizations, and clinics across the US, New Zealand, and Canada and co-developing research projects. Dr. Little is a white ally, registered nurse, and professor who has worked with Indigenous groups in food and health over the years. The first step in development was to determine if a repository would provide the Indigenous communities opportunities to access wise health practices, increase their cultural continuity, and support grassroots movements towards maximizing health. Though formal interviews were initially proposed, key community stakeholders requested more informal interviews and focus groups in the form of talking circles; written field notes and observations were collected at these meetings. Later, an online survey was completed and analyzed in a separate study.

After receiving Institutional Review Board exemption approval, between 2016-2017, the PI and Co-PI visited Indigenous communities and events in the US, Canada, and New Zealand to conduct key informant interviews on traditional medicines and food, with a focus on identifying digital food data needs. Participants were recruited via existing Indigenous research partner referrals. These participants were seen as "experts" in Indigenous food practices. The authors made contact via email or phone and requested an interview. After consent was given, data were documented via notes or audio recordings, which were destroyed after notes were taken. This part of the overall needs' assessment included individual formal and informal interviews with 13 Indigenous food or food sovereignty experts and/or traditional food medicine experts from the United States (American Indian, Alaska Native, and Native Hawaiian), Canada (First Nations), and New Zealand (Maori). Professional backgrounds included a range of Indigenous food activists, researchers, farmers, elders, and healthcare 
professionals. Age ranges were from 24 to $>75$. Participants were selected based on referrals from pre-identified Indigenous community leaders. The PIs then contacted key informants via phone, in person, and/or at another food health meeting/conference. Key informants included three elders, five persons working in healthcare or health research, two traditional healers, one program director, and two food sovereignty leaders and farmers.

Regarding food and digital repositories, the PIs asked the following questions: (1) How could an online platform be deemed suitable for Indigenous communities to catalogue food wisdom? (2) What types of information would be useful to classify? (3) What other related needs exist? Two additional talking circles were held at international Indigenous food-related conferences and meetings. The participants were asked to reflect on the above questions; the first two authors recorded field notes and analyzed results of individual interviews, as guided by the decolonizing (Smith 1999) and two-eyed seeing frameworks (Marsh et al. 2015; Bartlett et al. 2012). The researchers sought to provide space for Indigenous knowledges alongside any useful Western knowledge that may assist them. They reviewed field notes, identified themes and domains, and subcategorized, drawing from the consensual qualitative research (CQR) approach (Hill 2012). CQR is an inductive approach often used with small sample sizes and when open-ended interview questions are asked. The words were analyzed and multiple perspectives were considered. The first two authors coded all field notes and created domains and themes. The third author served as an external auditor. They used cross-referencing and were in consensus with the findings.

\section{Results}

The research team identified and agreed upon the themes portrayed in Table 1: (1) Sharing ancestral food practice data, (2) needing Indigenous community control of an online platform, and (3) the utility of wise food practices. A number of domains, or subthemes, were also categorized. Connection to land appeared important to participants, as most participants desired to conduct their individual interviews on the land, directly showing the growth of their food and/or offering food. Each of these themes is addressed in the following sections.

Table 1. Summary of themes and domains using the consensual qualitative approach.

\begin{tabular}{ll}
\hline Themes & Domains \\
\hline & (a) $\begin{array}{l}\text { Learn/reconnect with traditional food and land } \\
\text { practices within current climates } \\
\text { Revitalize land and food practices through } \\
\text { knowledge accessibility and exchange in a } \\
\text { digital multimedia format }\end{array}$ \\
$\begin{array}{ll}\text { Appropriate use: Sharing ancestral food and land } \\
\text { practice data online }\end{array}$ & (b) \\
\hline
\end{tabular}

$\begin{array}{ll} & \text { (a) } \begin{array}{l}\text { Indigenous community input and } \\ \text { data management }\end{array} \\ \text { Community control of Indigenous knowledge (IK) } & \text { (b) Include elders' knowledge in technology } \\ \text { (c) Use multimedia, including videos } \\ \text { and photographs }\end{array}$


(1) Appropriate use: Sharing ancestral food and land practice data online. Sharing ancestral food and land practices online was considered appropriate. Associated domains included (a) desiring to learn traditional food and land practices within current climates, and (b) desiring to revitalize land and food practices through knowledge accessibility and exchange in a digital format (Table 1). One participant noted that, simply put, "food is our medicine", and we need to utilize online resources "to grow this knowledge and get back in touch with the earth". Overall, participants confirmed having access to online resources for other purposes and saw it as an appropriate medium for sharing IKs. Even though participants discussed the need to share and access IKs online, they also spoke about the importance of reconnecting with the land. One participant discussed the need for their youth and community to reengage with the land. Another discussed the rainbow and it "connecting the sky, water, and earth, which bring forth our kai (food)". He then related the connections to food, water, and land by discussing the symbolism of animals within his culture. Similarly, a participant stated that the octopus "represents our connection to the water and the lands, as well as our connections to each other as Indigenous peoples". She then went on to discuss the trade system of foods between Indigenous peoples globally and the need to continue these exchanges by utilizing online resources. These experts also voiced a shared desire to reconnect with the land to revitalize traditional foods and knowledges. Several participants further mentioned the need to discuss food within the context of changing climates.

(2) Community control. The second theme highlighted the importance of community control of IKs and OIs with domains including (a) Indigenous community input and data management, (b) incorporating elder knowledge with technology, (c) the use of multimedia including videos and photographs, and (d) geographic information system (GIS) maps to portray data. For instance, a participant argued: "The community doesn't want our information taken and used, like usual. It would only be helpful if we had control over it and decided where that information went". Several participants discussed the fear of information being disseminated or misused without their control. It was suggested that including elder knowledge in technology would further cultural continuity and ensure that knowledge was displayed in culturally appropriate manners. "We really want our elders' voices recorded and available to the youth. We are going to lose that if we don't," stated one participant. Overall, participants voiced the desire to share information online, mapping traditional lands and food sources, but also limiting more sensitive information to tribal members only.

(3) Sharing wise practices. The third theme included the desire to identify and share wise practices through digital formats to improve health and wellbeing and to increase cultural continuity. This theme included the following domains: (a) Sharing practices and stories with others, (b) learning regional wise practices, (c) learning global practices that relate to environmental changes and ecosystems, and (d) how wise practices are currently used for healing. Several participants noted that wise practices were preferable to best practices. In fact, many Indigenous participants argued that Indigenous "ancestors knew best and what to keep us healthy". They discussed the need for furthering the wise practices that "actually work" as opposed to colonial-based practices. "We need to tell our own food stories, and I wouldn't mind learning what others are doing," stated a participant. The participants discussed the need to re-story or to tell their views of food and health as informed by their IKs and OIs.

\section{Discussion}

Ancestral wisdom has guided Indigenous peoples across generations into the digital age. While the utility of the Web was perhaps prophesized long ago, this study illustrates that Indigenous persons continue to envision the potential of digital platforms that provide opportunities to connect, reclaim, revitalize, and reinvent food wisdom. Specifically, this study found that key Indigenous community stakeholders from the US, Canada, and New Zealand shared the following views: (1) An online repository would be useful for sharing information about Indigenous food and ways to improve their health and wellbeing, (2) Indigenous communities need to remain in control of this knowledge, and (3) identifying and sharing wise practices may support cultural continuity by re-storying health. These 
findings are among the first to demonstrate global Indigenous community interest in utilizing an online repository to re-story and improve health and wellbeing by increasing cultural continuity. These findings will further help guide the development of a food wisdom repository for Indigenous land and food practices.

\subsection{Digital Platforms and Sharing IK}

Digital platforms like the suggested repository can create innovative spaces for sharing ancestral wisdom, storytelling, and re-storying of Indigenous teachings of health and wellbeing, as implied by our findings. Digital tools provide an opportunity to share information in multimedia formats that are consistent with decolonizing methodologies (Smith 1999). In this manner, Indigenous cultural teachings and worldviews can be centered in a digital platform, reflecting their worldview. This centering of IKs has been done previously in other research. For instance, Photovoice is a specific photographic technique that is compatible with Indigenous approaches to furthering knowledges. It enables participants to record the strengths and concerns of their communities, promote critical group dialog, and influence policymakers (Jennings et al. 2020; Jennings et al. 2018; Jennings and Lowe 2014; Wang and Burris 1997). Jennings and colleagues have shown that Photovoice can assist in centering the voices of Indigenous youth about foods in obesity interventions (Jennings and Lowe 2014; Jennings et al. 2018). By telling their stories through digital means, Western views of health are not imposed on Indigenous communities, but instead, others can view the world as they see it. This can also occur within an online platform, as communities can post their views of healthy food practices, which may or may not differ from Western views. An online digital platform can also host visual, oral, and written stories from Indigenous community perspectives and reach a wide global audience rapidly.

When considering the need to appropriately share ancestral information online, our findings led the investigators to propose an online map of traditional food and land practices for specific geographical locations. As mentioned before, our study supported notions that Indigenous groups living in the same ecoregion share more food and land practices than those Indigenous people who may be linguistically and culturally related but live apart. Thus, the online map will embed cultural narratives and storytelling around food practices for the region as dictated by elders and other knowledge keepers. At the same time, our findings further suggest that Indigenous control of their knowledges is critical. Thus, inputting knowledge cannot be overseen by those trained in Western research paradigms alone, especially if Indigenous participants seek to re-story views of their health from a story of deficit to one of strength. Communities must be engaged throughout the process.

Our findings also indicate that Indigenous communities wish to identify stories to be shared online and steward these within an open access platform. However, their stories need to retain their relational aspects. In particular, Western research paradigms often devalue stories by dissecting them, reducing them to individual parts, and then examining the parts, while often ignoring the relationships between them. In contrast, storytelling is a characteristic of Indigenous methodologies (Kovach 2015), and, as a whole, has many complicated layers. If broken apart and disconnected from the people, relational stories lose their meaning. Hence, stories require a relationship between the teller and receiver; they typically have a plot, an interrelated sequence of events. As Wilson (2008) explains, knowing the storyteller allows the receiver to assess their credibility. The broader importance of stories is their rootedness of IKs in land and place: "Our way of mapping our territory is through our stories. There is a story about every place. There are songs about each place. There are ceremonies that occur about those places. The songs, the stories, the ceremonies are our map" (p. 19, Little Bear 1998). Elders and other knowledge keepers can help identify which stories to share. Our findings further indicate that there is a need for including GIS technology. GIS software can facilitate mapping of ancestral and new stories that support healthy food practices while maintaining the relationships to the land and place. Thus, an online map with the embedded stories could maintain relationality to place and provide ongoing feedback from the community. 
As guided by the desire to share food and land practice, the researchers will further map the proposed regions by ecosystems, such as the Plains across North America, the Woodland regions, the Desert regions, Coastal regions, etc. The authors will then link Indigenous Nations who may be further removed from one another. For instance, the Anishinaabe peoples include multiple tribes who were separated during a mass migration, later during colonial assaults, and then more recently by government removal (American Indian Resource Center 2020). Thus, culturally and linguistically related Indigenous Nations exist across the Americas (i.e., the Ojibwe Anishinaabe in Canada and the US) and into Mexico (the Kickapoo Anishinaabe). Several key informants in this study indicated that these cultures still maintain similar cultural food and land practices. Hence, the proposed online platform will connect similar tribes and their tribal food and land practices. Indigenous stakeholders further wished to know how climate change and environmental pollution were affecting other Indigenous groups and their food practices across the world. Therefore, environmental changes must be considered alongside food practices and can serve to connect communities facing similar issues. This will further facilitate knowledge sharing and wise practices that may assist others, as the repository will include blogs and discussion groups.

Our findings further indicate that elders' knowledge is just as important as archival research findings. Their stories should also be included in such digital platforms, as indicated by other research (Marsh et al. 2015; Satterfield et al. 2016). Digital tools can address the need to maintain and utilize elder knowledge. For example, Satterfield et al. (2007) and colleagues indicate that elders remember a time before diabetes was rampant in Indigenous communities; they hold knowledge that can guide programming and policy development by identifying the factors that promote health. In addition to their held knowledge, elders play an essential role in knowledge translation (Ninomiya et al. 2017). Through use of a shared online digital platform, Indigenous knowledges will be centered, and Indigenous elders will be sought to support cultural continuity through sharing food and land practices that were once disrupted. Digitizing this knowledge keeps it available for future generations and furthers transmission across the generations.

\subsection{Indigenous Communities Maintaining Control of IK}

Secondly, there exists a dire need for Indigenous communities to maintain control of Indigenous knowledges (IK) and original instructions (OI) on an online platform, given the potential for cultural appropriation and misuse by outsiders. Indigenous community members wish to oversee both the input of data and online data management. Therefore, the digital online platform should not be seen as a mere tool to catalogue and categorize data by outsiders, but instead engage communities continually. The Tribal Health Sovereignty model supports Indigenous communities in maintaining control over their health and in taking charge in identifying specific Indigenous views of health that may vary from Western views (Jennings et al. 2018). Similarly, Indigenous data sovereignty (IDS) "is a critical part of this re-storying because, over time, non-Indigenous people with the power to select, record, and interpret data have colonized it ... . Information derived from implicitly or explicitly biased data will likely become single stories that range from liberating and empowering at one end to controlling and disempowering at the other" (Johnson-Jennings et al. 2019). Hence, re-storying and revitalization of food and land practices can change the narrative from one of deficit-i.e., focused on health disparities (e.g., obesity, cancer, diabetes) — to one of thrivance-i.e., focused on IKs related to relationships with foods and lands, wise practices, and ancestral stories that continue to guide these relationships and health.

Drawing from a community-engaged framework, a community advisory council of Elders from each region will be gathered to assist in identifying and stewarding the data. Elders have vast sources of knowledge and are highly esteemed in Indigenous communities. They can inform resilience strategies and share food and land narratives that may otherwise be missed (Kahn et al. 2016). Furthermore, Elder advisory councils serve an important role to advise and inform researchers about the appropriate use of data, community considerations, and if research is being conducted in a good way (Christopher 
et al. 2011). Elders can wisely assist with stewarding the data and unforeseen community concerns as well. Though the authors propose that Elders and key stakeholders control and steward the data, this must be done in a manner that continually supports Indigenous data sovereignty (IDS) (for a more thorough discussion of IDS and wise practices in relation to these findings and subsequent data collection, see Johnson-Jennings et al. 2019). IDS requires consulting with Indigenous communities at each step of the project; yet, the very nature of an online platform emphasizes the developer and user as having little interaction once the platform is complete. Indigenous methodologies support actively engaging Elders and other knowledge keepers throughout all steps of developing an online digital repository and in maintaining IDS.

Through using such a digital online software that can actively support IDS, the authors aim to establish geographical and national-/tribal-level Elders' Advisory Councils to oversee the identification of IKs, the most appropriate mediums for sharing, and the audiences with which to share. There are current examples of Indigenous communities overseeing and stewarding their online data as a collective whole, which may be useful for the proposed repository. One available platform providing for online stewardship is the Mukurtu software. Using this software, Indigenous communities can indigenize and digitize cultural protocol and secure specific web pages. Designated community leaders can further add videos, photographs, stories, and/or other content as they desire (Christen 2012). Again, based on our findings, the repository needs to be fluid and include multimedia shared in a manner that is protective of IKs (including videos, photographs, GIS maps, blogs, etc.), as well as ensuring that the community maintains ownership of all IKs uploaded. An Elders' Community Advisory Council in each region will be crucial in identifying who can manage the data, which data will be limited via passwords to local communities (including elders only or other specific sub-selected groups) or regional communities, and which data will be made publicly available. Examples of publicly available data may be community stories of successful gardening projects, organizations that increase healthy food access, or stories that relate to place and deemed appropriate to share with all, whereas password-protected data may include medical plants and their uses, stories specific to IKs of the region, and songs related to place. Again, the community will be in control of uploading this data, stewarding such through a community-appointed Elders' Advisory Council, and being able to remove content at will. Though data storage of these geographic regions and food and land practices will initially occur at the university, a more suitable long-term community site will be found as advised by the Elders' Advisory Council.

\subsection{Wise Practice Sharing}

Our final finding implies that Indigenous communities desire to share wise practices, rather than best practices, in order to learn about and improve food and health. Indigenous communities often consider wise practices culturally appropriate and more likely to lead to sustained change given that they center Indigenous worldviews and epistemologies (see Johnson-Jennings et al. 2019; Jennings et al. 2018; Satterfield et al. 2016). Privileging Indigenous worldviews remains important because ontological and epistemological beliefs drive methodology and methods, which then affect the credibility of results and their translation into evidence-based best practices (Wilson 2008). Likewise, credible Indigenous wise practices arise from Indigenous scientific research paradigms by way of their ontologies, epistemologies, methodologies, methods, results, and knowledge translation. Each paradigm has its own ways of realizing its very divergent aims: Generalizability versus sovereignty and self-determination. At the same time, global practices, healing, and a focus on environmental changes need to be included in the repository as desired by Indigenous communities. Therefore, the Food Wisdom Repository will be international in nature and will call for collective IKs and OIs sharing global wise practices that support thriving in the current world. Through sharing these practices, Indigenous communities may further their revitalization and reclamation of food practices in order to facilitate health and wellbeing. 


\section{Conclusions}

This study found that an online Food Wisdom Repository may contribute to the health and wellbeing of Indigenous peoples by supporting cultural continuity. Wise practices that include ancestral wisdom and original instructions can guide cultural continuity of Indigenous cultures and ever-evolving IKs, as they have for centuries. Even though colonization forced Indigenous persons into a survival mode in which some practices were taken, forgotten, or stagnated and which did not allow evolution with changing technologies and times, Indigenous communities have retained much knowledge that they now wish to share with others. This era of thrivance supports asserting data sovereignty and reclaiming, revitalizing, and reinventing IKs around cultural food and land practices through new technologies. However, Indigenous groups must remain engaged and in control throughout each step.

Author Contributions: D.J. and M.J.-J. conducted oversaw the research design, data collection and analysis. They further contributed to the writing of the original paper. They equally contributed to the overall project. As PI's. M.L. contributed as a co-investigator in verifying the data, contributed to the original paper, and provided overall administration for manuscript submission. All authors have read and agreed to the published version of the manuscript.

Funding: This research was funded by the Shakopee Mdewakanton Sioux SEEDS of Native Health FOOD repository development Award.

Conflicts of Interest: The authors declare no conflict of interest.

\section{References}

American Indian Resource Center. 2020. Anishinaabe Timeline. Available online: https://www.bemidjistate.edu/ airc/community-resources/anishinaabe-timeline/ (accessed on 3 April 2020).

Bartlett, Cheryl, Murdena Marshall, and Albert Marshall. 2012. Two-Eyed Seeing and Other Lessons Learned within a Co-Learning Journey of Bringing Together Indigenous and Mainstream Knowledges and Ways of Knowing. Journal of Environmental Studies 2: 331-40. [CrossRef]

Center for Digital Scholarship and Curation at Washington State University. 2019. Mukurtu. Available online: https://mukurtu.org/about/ (accessed on 12 December 2019).

Champagne, Duane. 2007. Social Change and Cultural Continuity among Native Nations; Lanham: Altamira Press. Available online: https://primo.lib.umn.edu/primo-explore/fulldisplay?docid= UMN_ALMA21458276110001701\&context=L\&vid=TWINCITIES\&lang=en_US\&search_scope=mncat_ discovery\&adaptor=LocalSearchEngine\&tab.=article_discovery\&query=any, contains $\quad$ (accessed on 13 March 2020).

Chandler, Michael J., and Christopher Lalonde. 1998. Cultural Continuity as a Hedge against Suicide in Canada's First Nations. Transcultural Psychiatry 35: 191-219. [CrossRef]

Christen, Kimberly A. 2012. Mukurtu: An Indigenous archive and publishing tool. Humanities Commons. [CrossRef]

Christopher, Suzanne, Robin Saha, Paul Lachapelle, Derek Jennings, Yoshiko Colclough, Clarice Cooper, Crescentia Cummins, Margaret J. Eggers, Kris FourStar, and Lennie Webster. 2011. Applying indigenous community-based participatory research principles to partnership development in health disparities research. Fam Community Health 34: 246-55. [CrossRef]

Donelle, Lorie, and Laurie Hoffman-Goetz. 2008. An Exploratory Study of Canadian Aboriginal Online Health Care Forums. Health Communication 23: 270-81. [CrossRef]

Hennessy, Kate, Natasha Lyons, Stephen Loring, Charles Arnold, Mervin Joe, Albert Elias, and James Pokiak. 2013. The Inuvialuit Living History Project: Digital Return as the Forging of Relationships Between Institutions, People, and Data. Museum Anthropology Review 7: 44-73. Available online: https://scholarworks.iu.edu/ journals/index.php/mar/article/view/2039/4246 (accessed on 2 February 2019).

Hill, Clara E. 2012. Consensual Qualitative Research: A Practical Resource for Investigating Social Science Phenomena. Worcester: American Psychological Association, Available online: https://www.apa.org/pubs/books/4313031 (accessed on 2 February 2019). 
Hunter, Jane. 2005. The Role of Information Technologies in Indigenous Knowledge Management. Australian Academic E Research Libraries 36: 109-24. [CrossRef]

Jennings, Derek, and John Lowe. 2014. Photovoice: Giving Voice to Indigenous Youth. Pimatisiwin: A Journal of Aboriginal and Indigenous Community Health 11: 521-37. Available online: http://www.pimatisiwin.com/ online/wp-content/uploads/2014/02/15Jennings.pdf (accessed on 2 February 2017).

Jennings, Derek, Meg M. Little, and Michelle Johnson-Jennings. 2018. Developing a Tribal Health Sovereignty Model for Obesity Prevention. Progress in Community Health Partnerships 12: 353-62. [CrossRef]

Jennings, Derek R., Koushik Paul, Meg M. Little, Daryl Olson, and Michelle D. Johnson-Jennings. 2020. Identifying Perspectives About Health to Orient Obesity Intervention Among Urban, Transitionally Housed Indigenous Children. Qualitative Health Research 30: 894-905. [CrossRef]

Johnson-Jennings, Michelle, Derek Jennings, and Meg M. Little. 2019. Indigenous Data Sovereignty in Action: The Food Wisdom Repository. Journal of Indigenous Wellbeing. Te Mauri Pimatisiwin 4: 26-38. Available online: https://journalindigenouswellbeing.com/media/2019/07/121.127.Indigenous-data-sovereignty-inaction-The-Food-Wisdom-Repository.pdf (accessed on 21 July 2019).

Johnson-Jennings, Michelle, Derek Jennings, Koushik Paul, and Meg Little. Forthcoming. An Indigenous Food Wisdom Repository: Needs and Uses for Digital Indigenous Food Knowledge and Practices.

Kahn, Carmella B., Kerstin Reinschmidt, Nicolette I Teufel-Shone, Christina E Oré, Michele Henson, and Agnes Attakai. 2016. American Indian Elders' resilience: Sources of strength for building a healthy future for youth. American Indian and Alaska Native Mental Health Research 23: 117-33. [CrossRef] [PubMed]

Kovach, Margaret. 2015. Emerging from the Margins: Indigenous Methodologies. In Research as Resistance: Revisiting Aritical, Indigenous, and Anti-Oppressive Approaches, 2nd ed. Edited by Leslie Brown and Susan Strega. Toronto: Canadian Scholars' Press, pp. 43-64. Available online: https://books.google.com/books?hl=en\& $\mathrm{lr}=\& \mathrm{id}=4 \mathrm{UNVCgAAQBAJ} \& \mathrm{i}=\mathrm{fnd} \& \mathrm{pg}=\mathrm{PA} 43 \& \mathrm{dq}=$ decolonizing + methodologies\&ots=WMy8Xv9TfK\& sig=goWqN-k8tosCfKIpdEXay8moLCA\#v=onepage\&q=decolonizingmethodologies\&f=false (accessed on 2 March 2019).

Little Bear, Leroy. 1998. Aboriginal Relationships to the Land and Resources. In Sacred Lands: Aboriginal World Views, Claims, and Conflicts. Edited by Jill Oakes, Rick Riewe, Kathi Kinew and Elaine L. Maloney. Edmonton: The University of Alberta Press, pp. 15-20. Available online: http://www.uap.ualberta.ca/titles/ 762-9781896445076-sacred-lands (accessed on 2 February 2019).

Lynn, Kathy. 2013. The impacts of climate change on tribal traditional foods. Climatic Change 120: 5454-556. [CrossRef]

Marsh, Teresa Naseba, Sheila Cote-Meek, Pamela Toulouse, Lisa M. Najavits, and Nancy L. Young. 2015. The Application of Two-Eyed Seeing Decolonizing Methodology in Qualitative and Quantitative Research for the Treatment of Intergenerational Trauma and Substance Use Disorders. International Journal of Qualitative Methods 14: 1-13. [CrossRef]

Martin, Karen, and Booran Mirraboopa. 2003. Ways of Knowing, Being and Doing: A Theoretical Framework and Methods for Indigenous and Indigenist Re-search. Journal of Australian Studies 27: 203-14. [CrossRef]

Moreton-Robinson, Aileen, Jean O'Brien, and Chris. Andersen. 2017. Relationality: A Key Presupposition of an Indigenous Social Research Paradigm. London: Routledge.

Mould, Tom. 2003. Choctaw Prophecy: A Legacy for the Future. Tuscaloosa: University of Alabama Press.

Nelson, Melissa K. 2008. Original Instructions: Indigenous Teachings for a Sustainable Future. Rochester: Bear \& Company.

Ninomiya, Melody M., Donna Atkinson, Simon Brascoupé, Michelle Firestone, Nicole Robinson, Jeff Reading, Carolyn P. Ziegler, Raglan Maddox, and Janet K. Smylie. 2017. Effective Knowledge Translation Approaches and Practices in Indigenous Health Research: A Systematic Review Protocol. Systematic Reviews 6: 34. [CrossRef] [PubMed]

Oster, Richard T., Angela Grier, Rick Lightning, Maria J. Mayan, and Ellen L. Toth. 2014. Cultural Continuity, Traditional Indigenous Language, and Diabetes in Alberta First Nations: A Mixed Methods Study. International Journal for Equity in Health 13. [CrossRef] [PubMed]

Saslis-Lagoudakis, C. Haris, Julie Hawkins, Simon J. Greenhill, Colin A. Pendry, Mark F. Watson, Will Tuladhar-Douglas, Sushim R. Baral, and Vincent Savolainen. 2014. The Evolution of Traditional Knowledge: Environment Shapes Medicinal Plant Use in Nepal. Proceedings of the Royal Society B Biological Sciences 281: 20132768. [CrossRef] [PubMed] 
Satterfield, Dawn, John Eagle Shield, John Buckley, and Sally Taken Alive. 2007. So That the People May Live (Hecel Lena Oyate Ki Nipi Kte): Lakota and Dakota Elder Women as Reservoirs of Life and Keepers of Knowledge about Health Protection and Diabetes. Journal of Health Disparities Research and Practice 1: 1-28. Available online: http://digitalscholarship.unlv.edu/jhdrp/vol1/iss2/2/ (accessed on 3 March 2019).

Satterfield, Dawn, Lemyra DeBruyn, Marjorie Santos, Larry Alonso, and Melinda Frank. 2016. Health Promotion and Diabetes Prevention in American Indian and Alaska Native Communities-Traditional Foods Project, 2008-2014. MMWR Supplement 65: 4-10. [CrossRef]

Smith, Linda Tuhiwai. 1999. Decolonizing Methodologies, 1st ed. New York: Zed Books Limited.

Thoms, J. Michael. 2007. Leading an Extraordinary Life: Wise Practices for an HIV Prevention Campaign with Two-Spirit Men. Toronto. Available online: http://2spirits.com/PDFolder/Extraodinarylives.pdf (accessed on 3 March 2019).

Tupper, Jennifer. 2014. Social Media and the Idle No More Movement: Citizenship, Activism and Dissent in Canada. Journal of Social Sciences Education 13: 87-94. [CrossRef]

Walters, Karina L., Michelle Johnson-Jennings, Sandra Stroud, Stacy Rasmus, Billy Charles, Simeon John, James Allen, Joseph Keawe'aimoku Kaholokula, and Mele A. Look. 2018. Growing from Our Roots: Strategies for Developing Culturally Grounded Health Promotion Interventions in American Indian, Alaska Native, and Native Hawaiian Communities. Prevention Science 21: 54-64. [CrossRef]

Wang, C. C., and Mary Ann Burris. 1997. Photovoice: Concept, Methodology, and Use for Participatory Needs Assessment. Health Education \& Behavior 24: 369-87. [CrossRef]

Wesley-Esquimaux, Cynthia, and Brian Calliou. 2010. Best Practices in Aboriginal Community Development: A Literature Review and Wise Practices Approach. Banff. Available online: https://www.researchgate.net/profile/Brian_Calliou/publication/259176947_Best_Practices_in_ Aboriginal_Community_Development_A_Literature_Review_and_Wise_Practices_Approach/links/ 0c96052a20ef28dfa1000000/Best-Practices-in-Aboriginal-Community-Development-A (accessed on 3 March 2019).

Wilson, Shawn. 2008. Research Is Ceremony: Indegenous Research Methods. Winneoeg: Fernwood.

(C) 2020 by the authors. Licensee MDPI, Basel, Switzerland. This article is an open access article distributed under the terms and conditions of the Creative Commons Attribution (CC BY) license (http://creativecommons.org/licenses/by/4.0/). 